\title{
Zero-Liquid Discharge Treatment of Wastewater from a Fertilizer Factory
}

\author{
Svetlana B. Zueva ${ }^{1,2}$, Francesco Ferella ${ }^{1, *}{ }^{\mathbb{C}}$, Giuliana Taglieri ${ }^{1}{ }^{\mathbb{D}}$, Ida De Michelis ${ }^{1}$, \\ Inna Pugacheva ${ }^{2}$ and Francesco Vegliò ${ }^{1}$ \\ 1 Department of Industrial and Information Engineering and Economics, University of L'Aquila, \\ 67100 L'Aquila, Italy; svetlana.zueva@graduate.univaq.it (S.B.Z.); giuliana.taglieri@univaq.it (G.T.); \\ ida.demichelis@univaq.it (I.D.M.); francesco.veglio@univaq.it (F.V.) \\ 2 Department of Chemical Engineering, Voronezh State University of Engineering, 394036 Voronezh, Russia; \\ eco-inna@yandex.ru \\ * Correspondence: francesco.ferella@univaq.it
}

Received: 10 December 2019; Accepted: 1 January 2020; Published: 3 January 2020

check for updates

\begin{abstract}
This article describes the improvement of wastewater treatment in a fertilizer plant located in Central Italy (municipality of Vasto). In this facility, water is used for the removal of dust and fluorinated gases from the air. The resulting wastewater contains fluorides and phosphates in hazardous forms. Its treatment ordinarily does not result in a Zero-Liquid Discharge (ZLD) process. To achieve this purpose, several reagents were tested, focusing on the correlation linking $\mathrm{pH}$, type of reagent and the effect on the separation of fluorides and phosphates from the wastewater. It was eventually found, and explained with a model, that hydrated lime at $\mathrm{pH}=12$ was so effective as a precipitating agent that phosphate and fluoride separation reached a value of $99.9 \%$, thus allowing for reuse of the water in the plant process. Furthermore, phosphates and fluorides precipitated in a non-hazardous form, so that the material could also be recycled. In synthesis, wastewater treatment of the fertilizer plant was upgraded so that it became a ZLD process coupled with the recovery and recycling of fluorides and phosphates.
\end{abstract}

Keywords: fluoride; phosphates; separation; ZLD; fertilizer; wastewater

\section{Introduction}

The raw materials for the production of phosphate fertilizers, phosphoric acid, and elemental phosphorus are natural phosphate ores like apatite and phosphorite. The main component of these phosphorus double salts is tricalcium phosphate, whose raw chemical formula is $3 \mathrm{Ca}_{3}\left(\mathrm{PO}_{4}\right)_{2} \cdot \mathrm{CaX}$, where $\mathrm{X}=\mathrm{F}^{-}, \mathrm{OH}^{-}$, and $\mathrm{Cl}^{-}$. Apart from this, such raw materials can also contain $\mathrm{CaCO}_{3}(7 \%-13 \% \mathrm{wt})$, $\mathrm{SiO}_{2}(1 \%-8 \%), \mathrm{CaSO}_{4}(1 \%-5 \%), \mathrm{CaF}_{2}(4 \%-8 \%), \mathrm{Al}_{2} \mathrm{O}_{3}(1 \%-1.5 \%), \mathrm{Fe}_{2} \mathrm{O}_{3}(0.5 \%-1 \%), \mathrm{MgO}(0.3 \%-0.6 \%)$. In the manufacturing process of phosphate fertilizers, raw material containing phosphorus in the form of $\mathrm{Ca}_{3}\left(\mathrm{PO}_{4}\right)_{2}$, which is an insoluble and poorly available form for plants, is chemically treated by sulfuric acid to obtain a product with a high concentration of $\mathrm{P}_{2} \mathrm{O}_{5}$, which can be easily absorbed by plants.

During acidulation of phosphate rock to produce phosphoric acid or superphosphates, fluoride is released as hydrofluoric acid HF, which in turn reacts with silica forming the volatile gas silicon tetrafluoride $\mathrm{SiF}_{4}$ and hydro-soluble hexafluorosilicic acid $\mathrm{H}_{2} \mathrm{SiF}_{6}$. Both of these are partially carried along in the wastewaters coming from the operations of gaseous waste scrubbing and phosphogypsum transportation performed during the processing of phosphate rock [1]. Wastewater from the industrial production of phosphate fertilizers is generated in a relatively small quantity. However, it contains very fine suspended solids and a high concentration of hazardous substances (phosphoric acid $\mathrm{H}_{3} \mathrm{PO}_{4}$, 
hydrofluoric acid $\mathrm{HF}$, and hexafluorosilicic acid $\mathrm{H}_{2} \mathrm{SiF}_{6}$ ) which make purification treatments difficult. Chemical precipitation can be suggested as the most adopted method. But, in turn, the complex chemical structure of sediments makes it un-economical to re-use them in any form. As a result, the fertilizer industry discharges wastewater into the environment, including several thousand tons of fluorides per year and even more phosphates.

Methods of recovering silica from waste hexafluorosilicic acid from the fertilizer industry for applications such as chromatography and reinforcing material for rubber and plastics have been reported [1,2].

Fluorides and phosphates can be removed from wastewater using several treatments, such as biological and physical-chemical methods. Methods of removal include precipitation [3], microfiltration [4], electrocoagulation [5], reverse osmosis (RO), nanofiltration (NF) [6], selective separation [7] and fluoride removal in a fluidized bed reactor [8].

For example, hexafluorosilicic acid can be neutralized with sodium hydroxide or sodium carbonate, with the resulting precipitation of sodium fluorosilicate. Sodium chloride can also be used as a precipitating agent for the same purpose.

It is used as a fluoridation agent for drinking water, insecticide, production of high purity silicon tetrafluoride and the production of enamels for china and porcelain products [9].

Furthermore, phosphorous and fluorides can be recycled as raw materials in either agricultural or industrial applications. For instance, calcium fluoride and calcium phosphate-based by-products can be used in several industrial sectors, such as ceramic manufacturing and phosphate fertilizer industries [10].

In most chemical treatments, phosphorus can be removed by precipitation with a metal salt, e.g., iron, aluminum and calcium salts [11]. In wastewater with high fluoride content, the most commonly adopted method is precipitation under calcium fluoride form $\left(\mathrm{CaF}_{2}\right)$, using different calcium salts $\left(\mathrm{CaCl}_{2}, \mathrm{Ca}\left(\mathrm{NO}_{3}\right)_{2} \cdot 4 \mathrm{H}_{2} \mathrm{O}\right.$, and hydrated lime $\left.\mathrm{Ca}(\mathrm{OH})_{2}\right)$ as precipitants [12-14].

However, precipitation by the use of metal salts and lime results in the formation of a large quantity of sludge which is difficult to treat for the extraction of valuable components $[15,16]$.

The overall research was designed to study a neutralization/precipitation-based process using $\mathrm{NaCl}, \mathrm{KOH}, \mathrm{NaOH}$ and hydrated lime as precipitating agents in the treatment of wastewater from the fertilizer industry containing phosphate and fluoride ions, the latter in the $\mathrm{HF}$ and $\mathrm{H}_{2} \mathrm{SiF}_{6}$ forms in a wide range of $\mathrm{pH}$, from 1.5 up to 12 .

Sodium chloride was chosen as a reagent for the neutralization of hexafluorosilicic acid with the formation of non-hazardous sodium fluoride and sodium fluorosilicate. Fluoride precipitation in calcium fluoride form $\left(\mathrm{CaF}_{2}\right)$ caused by hydrated lime was chosen as it is the most commonly adopted method. Potassium and sodium hydroxide were chosen as an alternative to hydrated lime in order to decrease the volume of the precipitated solids.

Due to the high odor intensity of the studied wastewater, special attention was paid to its removal after treatment.

This experimental study resulted in the discovery of the optimal reagent and parameters of a process that made the conversion of phosphate and fluoride into non-hazardous materials in a Zero-Liquid Discharge (ZLD) process.

\section{Materials and Methods}

\subsection{Chemicals and Solutions}

The experiments were carried out using real wastewater collected from the Puccioni S.p.a fertilizer plant (Vasto, Italy).

Hydrated lime (calcium hydroxide $10 \% \mathrm{wt} / \mathrm{vol}$ ), sodium hydroxide $10 \% \mathrm{wt} / \mathrm{vol}$, potassium hydroxide $10 \% \mathrm{wt} / \mathrm{vol}$, sodium chloride $10 \% \mathrm{wt} / \mathrm{vol}$ and epichlorohydrin-dimethylamine (EPI-DMA) were used for the precipitation tests. 
For all the fluoride-containing solutions, only polypropylene (PP) vessels were used for sample preparation and storage.

\subsection{Analytical Methods}

The analysis of phosphates and fluorides contained in acid mixtures is rather difficult from the analytical point of view, and this has already been the subject of some recent works [17]. For instance, in the case of phosphate industry effluents, the presence of the poly-acid $\mathrm{H}_{3} \mathrm{PO}_{4}$ next to $\mathrm{H}_{2} \mathrm{SiF}_{6}$ and HF makes the mixture even more complex from an analytical point of view [18]. Hexafluorosilicic acid $\mathrm{H}_{2} \mathrm{SiF}_{6}$ has a complex and widely unresolved speciation [19]. Consequently, the analysis of $\mathrm{H}_{2} \mathrm{SiF}_{6}$ containing an acid mixture is usually considered as a complicated case. In the present work, the exact concentration of each acid solution was initially determined by potentiometric titration of acid mixtures.

Titrations were performed by using an HF resistant glass electrode (Metrohm-60, 421.100). The titrant was a $9.53 \cdot 10^{-2} \mathrm{~mol} / \mathrm{L} \mathrm{NaOH}$ solution.

An X-ray fluorescence (XRF) spectrophotometer (Spectro XEPOS 2000) and a fast sequential atomic absorption spectrometer (AAS, Varian AA240FS) were used to perform the chemical analyses of the wastewater and the precipitate from wastewater.

Both Fourier-transform infrared spectroscopy (FTIR, Impact 410 Nicolet spectrophotometer, SpectraLab, Alexandria, VA, USA) and X-ray diffraction (XRD, X'Pert PRO diffractometer, Panalytical, Malvern, UK) were used to characterize the obtained precipitates.

All the quantitative analyses were carried out three times, and the results in the figures and tables are expressed as average values.

The analysis of the wastewater odor intensity was determined by using a sensory method in which 10 raters were asked to judge the odor. Odor intensity was evaluated by following the odor panel presented in Table 1, where the intensity level changes from 6 (extremely strong) to 0 (not perceptible).

Table 1. Odor intensity categories [20].

\begin{tabular}{cc}
\hline Odor Strength & Intensity Level \\
\hline Extremely strong & 6 \\
Very strong & 5 \\
Strong & 4 \\
Distinct & 3 \\
Weak & 2 \\
Very weak & 1 \\
Not perceptible & 0 \\
\hline
\end{tabular}

\subsection{Flocculation Experiments}

The flocculation experiments were carried out in a jacketed stirred tank reactor. The time and speed for mixing were set with an automatic controller.

The flocculation behavior of wastewater was investigated for cationic flocculant, EPI-DMA, in concentrations ranging from 1 to $20 \mathrm{mg} / \mathrm{L}$. To finely set the dosage of the EPI-DMA (initial viscosity equal to $3200 \mathrm{mPa} \cdot \mathrm{s}$ ) in the experiments, the flocculant was provided using $10 \% \mathrm{wt}$ solution in distilled water.

The flocculation experiments were conducted to determine the effect of the EPI-DMA dosage on the separation efficiency (measured by the total suspended solids (TSS) content of the residual liquor) and the relevant effect on $\mathrm{K}^{+}$and $\mathrm{Cl}^{-}$dissolution.

Subsequently, the precipitate was filtered by a vacuum pump (XX1004700, Millipore, Milano, Italy) and the solution was stored for XRF and AAS analyses. Filter cakes were dried at $105^{\circ} \mathrm{C}$ for $24 \mathrm{~h}$ and prepared for the XRD, XRF and FTIR analysis. 


\subsection{Precipitation Tests}

During the precipitation stage, the reagents were gradually added under constant stirring until reaching the desired $\mathrm{pH}$. The mixture was stirred further for $2 \mathrm{~h}$ to ensure precipitation equilibrium. Precipitation tests were performed in a $\mathrm{pH}$ range of $1.5-12$, at room temperature $\left(25 \pm 2{ }^{\circ} \mathrm{C}\right)$.

Precipitation tests in the $\mathrm{pH}$ range of $\mathrm{pH} 1.5-2$ were performed with sodium chloride and in the $\mathrm{pH}$ range of $\mathrm{pH} 2-12$ with metal hydroxides.

The final $\mathrm{pH}$ was measured and the precipitate separated from the slurry by vacuum filtration, washed three times with demineralized water and then dried at $105{ }^{\circ} \mathrm{C}$ overnight. For each considered $\mathrm{pH}$, the obtained filtrate was analyzed for determining the residual $\mathrm{PO}_{4}{ }^{3-}, \mathrm{SiF}_{6}{ }^{2-}, \mathrm{F}^{-}$ions content.

The $\mathrm{pH}$ after precipitation tests with metal hydroxides was adjusted to 2.0 before starting titration, by adding $\mathrm{HCl}$ to the wastewater.

The amount of precipitated fluoride or phosphate ions was expressed in term of removal efficiency calculated as follows,

$$
\text { Removal }(\%)=\frac{C_{0}-C_{P}}{C_{0}} \cdot 100
$$

where $C_{0}$ is the initial concentration and $C_{P}$ is the concentration after precipitation $(\mathrm{mg} / \mathrm{L})$.

\section{Results and Discussion}

In this section, a quick overview of the main results achieved during the experimental campaign is given. After the characterization of two different wastewater samples, the effect of the flocculant was reported, hence the results obtained after the addition of $\mathrm{NaCl}$ and $\mathrm{KOH}$ or $\mathrm{NaOH}$ were discussed, together with the analysis of the chemistry and the precipitation mechanisms of fluorides and phosphates caused by lime. In the end, a process flow-sheet was proposed to recycle all the water recovered from the fertilizer manufacturing plant.

\subsection{Characterization of the Wastewater}

The experiments were performed on two samples of wastewater, taken on two different days after a scrubber treatment, containing both soluble and insoluble phosphates and fluorides.

The composition of the liquid and solid phase of the wastewater resulting from the scrubber varies considerably depending on the kind of raw material (phosphates) used for the fertilizer production. Tables 2 and 3 show the results of the analysis carried out with XRF.

Table 2. Semi-quantitative analysis of the solid and liquid phase of the wastewater.

\begin{tabular}{|c|c|c|c|c|c|c|c|}
\hline \multirow{2}{*}{$\begin{array}{c}\text { Wastewater } \\
\text { Sample }\end{array}$} & \multicolumn{7}{|c|}{ Concentration $(\% w t)$} \\
\hline & Al & Si & $\mathrm{Ca}$ & $\mathrm{Fe}$ & $\mathbf{S}$ & $\mathrm{Cl}$ & $\mathbf{P}$ \\
\hline \multicolumn{8}{|c|}{ Solid Phase } \\
\hline $\mathrm{I}$ & 0.12 & 86.72 & 8.28 & 0.31 & 0.64 & 0.27 & 3.54 \\
\hline II & 0.35 & 84.01 & 8.08 & 1.21 & 0.34 & 0.15 & 5.55 \\
\hline \multicolumn{8}{|c|}{ Liquid Phase } \\
\hline $\mathrm{I}$ & 0.056 & 1.733 & 0.430 & 0.005 & 0.033 & 0.207 & 0.346 \\
\hline II & 0.600 & 2.179 & 1.525 & 0.011 & 0.495 & 0.279 & 0.834 \\
\hline
\end{tabular}

Table 3. Semi-quantitative analysis of the raw materials.

\begin{tabular}{cccccccc}
\hline \multirow{2}{*}{ Raw Material } & \multicolumn{7}{c}{ Concentration (\%wt) } \\
\cline { 2 - 8 } & Al & Si & Ca & Fe & S & Cl & P \\
\hline Morocco & 0.28 & 2.66 & 25.5 & 0.44 & 0.25 & 0.01 & 6.73 \\
Senegal & 0.96 & 1.45 & 24.44 & 1.28 & 0.14 & 0.004 & 9.63 \\
\hline
\end{tabular}


The suspended solids contained in the wastewater were composed of the raw materials used for the production of the phosphate fertilizers after decomposition by acid, in particular $\mathrm{CaO}, \mathrm{P}_{2} \mathrm{O}_{5}, \mathrm{CaF}$, $\mathrm{Al}_{2} \mathrm{O}_{3}$, and $\mathrm{SiO}_{2}$. Soluble impurities were composed of $\mathrm{PO}_{4}{ }^{3-}, \mathrm{F}^{-}$, and $\mathrm{SiF}_{6}{ }^{2-}$ ions.

The exact concentrations of $\mathrm{PO}_{4}{ }^{3-}, \mathrm{F}^{-}$, and $\mathrm{SiF}_{6}{ }^{2-}$ in the wastewater were determined by potentiometric titrations. Three separated equivalence points can be clearly recognized from the potentiometric titration curves (Figure 1) and can be related to the reactions listed in Table 4.

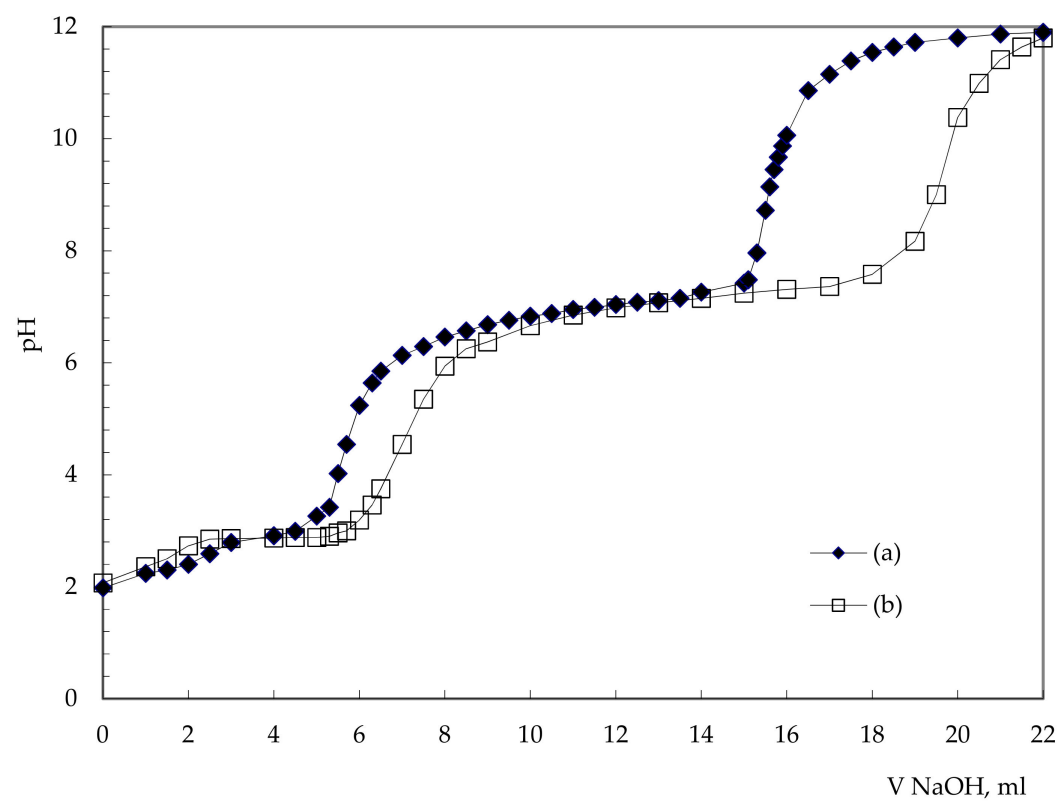

Figure 1. Potentiometric titration curves with $9.53 \cdot 10^{-2} \mathrm{~mol} / \mathrm{L} \mathrm{NaOH}$ in $15 \mathrm{~mL}$ of wastewater: (a) $\mathrm{n}^{\circ}$; (b) $\mathrm{n}^{\circ} 2$.

Table 4. Equilibrium equations of the E-pH diagram.

\begin{tabular}{ccccc}
\hline \multirow{2}{*}{ pKa [21] } & $\mathbf{p H}$ & Equilibrium Equations & \multicolumn{2}{c}{$\mathbf{P}-\mathbf{F}-\mathrm{Si}-\mathrm{H}_{\mathbf{2}}$ O System } \\
\cline { 3 - 4 } & & $\mathbf{p H}$ & Equivalence Point \\
\hline 1.7 & 3.5 & $\mathrm{H}_{2} \mathrm{SiF}_{6} \leftrightarrow \mathrm{SiF}_{6}^{2-}+2 \mathrm{H}^{+}$ & \\
2.1 & 4.6 & $\mathrm{H}_{3} \mathrm{PO}_{4} \leftrightarrow \mathrm{H}_{2} \mathrm{PO}_{4}^{-}+\mathrm{H}^{+}$ & first \\
3.1 & 7.0 & $\mathrm{HF} \leftrightarrow \mathrm{H}^{+}+\mathrm{F}^{-}$ & 2.4 & \\
3.9 & 8.6 & $\mathrm{SiF}_{6}^{2-}+2 \mathrm{H}_{2} \mathrm{O} \leftrightarrow 6 \mathrm{~F}^{-}+4 \mathrm{H}^{+}+\mathrm{SiO}_{2}$ & 4.3 & second \\
7.4 & 9.6 & $\mathrm{H}_{2} \mathrm{PO}_{4}^{-} \leftrightarrow \mathrm{HPO}_{4}^{2-}+\mathrm{H}^{+}$ & 9.4 & third \\
\hline
\end{tabular}

The concentrations of phosphates and fluorides in the wastewater were calculated and listed in Table 5, based on titration data (Figure 1).

Table 5. Chemical composition of the wastewater.

\begin{tabular}{ccccc}
\hline \multirow{2}{*}{$\begin{array}{c}\text { Wastewater } \\
\text { Sample }\end{array}$} & $\mathbf{p H}$ & \multicolumn{3}{c}{ Concentration $(\mathrm{g} / \mathrm{L})$} \\
\cline { 3 - 5 } & & $\mathbf{P O}_{4}{ }^{3-}$ & $\mathbf{S i F}_{\mathbf{6}}{ }^{\mathbf{}}$ & $\mathbf{F}^{-}$ \\
\hline Sample I & 1.86 & 59.88 & 6.96 & 1.68 \\
Sample II & 1.97 & 76.83 & 13.76 & 0.58 \\
\hline
\end{tabular}

Table 2 shows the elemental composition of the wastewater and its precipitate according to the XRF measurements. The concentrations of $\mathrm{PO}_{4}{ }^{3-}, \mathrm{F}^{-}$and $\mathrm{SiF}_{6}{ }^{2-}$ in the wastewater shown in Table 5 are calculated on the basis of the titration curves. Table 5 shows in which form the fluorine compounds are present in wastewater. The authors measured fluoride under the HF form and the fluoride silicate complex. 
To cross-check the reliability of the above table, three model solutions were prepared with $78.6 \mathrm{~g} / \mathrm{L}$ of $\mathrm{PO}_{4}{ }^{3-}$ and $4.8 \mathrm{~g} / \mathrm{L}$ of $\mathrm{F}^{-}$. The relevant titration curves were plotted (Figure 2). The recalculated concentration values were $76.8 \mathrm{~g} / \mathrm{L}$ of $\mathrm{PO}_{4}{ }^{3-}$ and $4.5 \mathrm{~g} / \mathrm{L}$ of $\mathrm{F}^{-}$.

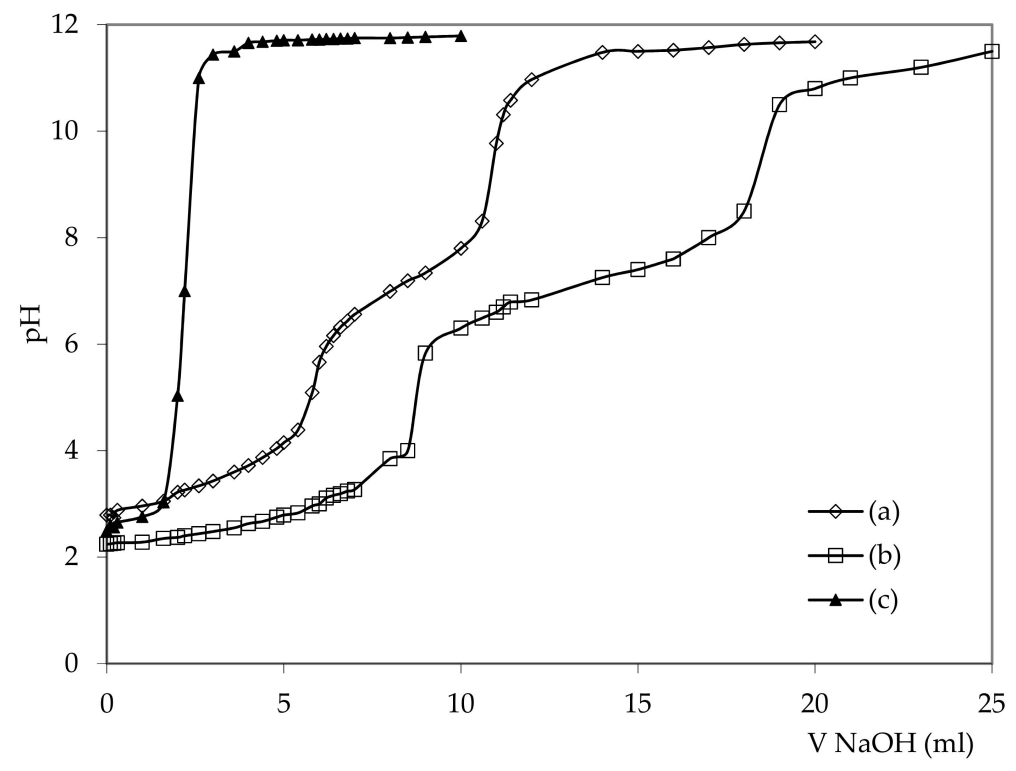

Figure 2. Potentiometric titration curves of model solutions containing: (a) $\mathrm{H}_{3} \mathrm{PO}_{4}$ and $\mathrm{HF}$ mixture, (b) $\mathrm{H}_{3} \mathrm{PO}_{4}$ and (c) HF.

\subsection{Wastewater Treatment}

\subsubsection{Effect of Flocculant}

The studied wastewater contains suspended and nanosized solids that originated from the particles of the raw material. The flocculation of the suspension was studied at $\mathrm{pH} 1.8$ (sample I) and 1.9 (sample II). The effect of EPI-DMA dosage on the TSS, fluorides, phosphates, and odor is shown in Figure 3. The flocculation rate increased with the increase of the EPI-DMA concentration; it reached a maximum and then decreased. According to the results of the experiments, the flocculant was helpful in forming flocks (Figure 4) and furthering fast sedimentation, but did not show good efficiency in phosphate, fluoride or odor removal.

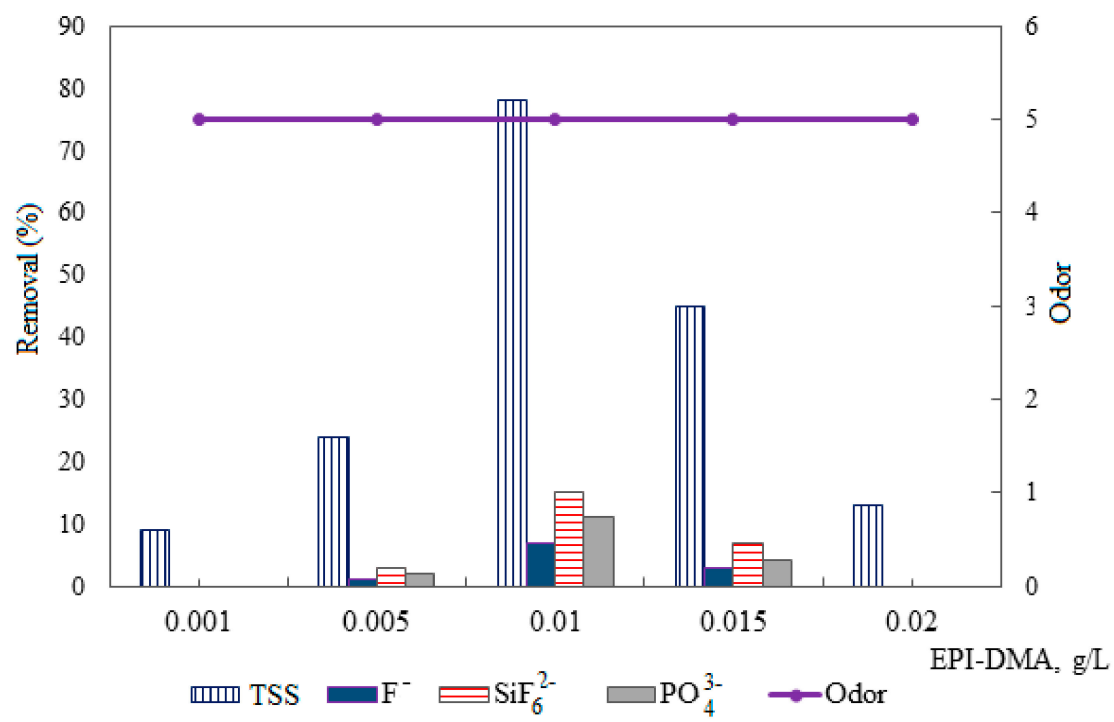

Figure 3. Effect of epichlorohydrin-dimethylamine (EPI-DMA) dosage on contaminant removal. 


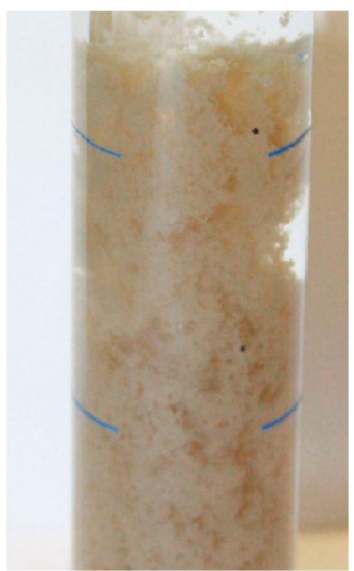

(a)

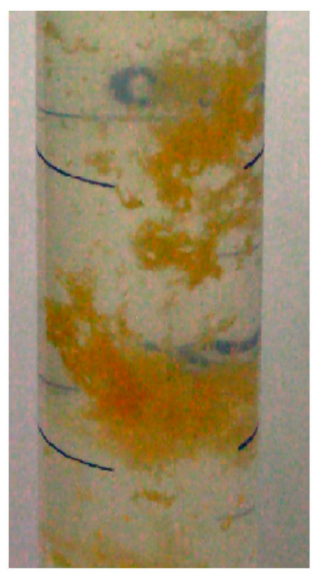

(b)

Figure 4. Flocculation effect of EPI-DMA (0.01 g/L): (a) Sample I; (b) Sample II.

\subsubsection{Effect of Sodium Salt}

As said above, sodium chloride was chosen as a reagent for the neutralization of hexafluorosilicic acid with the formation of sodium fluorosilicate (Table 6). The use of sodium chloride or sodium hydroxide leads to the formation of coarser sodium hexafluorosilicate and precipitation of amorphous silica, which plays the role of active centers for deposition of phosphate and fluoride ions. Different amounts of $\mathrm{NaCl}$ were added to the wastewater sample in order to reach the desired $\mathrm{pH}$ value. It was found that, along with a decrease in the $\mathrm{pH}$ value from 1.7 to 1.5 , the removal efficiency of $\mathrm{SiF}_{6}{ }^{2-}$ increased from $41 \%$ up to $74 \%$ and then decreased (Figure $4 \mathrm{a}$ ). The precipitation of $\mathrm{SiF}_{6}{ }^{2-}$ contained in wastewater by the addition of sodium chloride relies on the formation of sodium fluorosilicate at $\mathrm{pH} 1.7-1.5$ and its dissolving at $\mathrm{pH}<1.5$.

Table 6. Fluoride, phosphate and fluorosilicate precipitate formation at different $\mathrm{pH}$ levels.

\begin{tabular}{|c|c|c|}
\hline $\mathrm{pH}$ & $\mathrm{P}-\mathrm{F}-\mathrm{Si}-\mathrm{Na}(\mathrm{K})-\mathrm{H}_{2} \mathrm{O}$ System & P-F-Si-(Na-Cl)-Ca- $\mathrm{H}_{2} \mathrm{O}$ System \\
\hline $2-1.5$ & - & $\mathrm{H}_{2} \mathrm{SiF}_{6}+2 \mathrm{NaCl} \rightarrow \mathrm{Na}_{2} \mathrm{SiF}_{6} \downarrow+2 \mathrm{HCl}$ \\
\hline $2-6$ & $\begin{aligned} \mathrm{H}_{2} \mathrm{SiF}_{6}+2 \mathrm{NaOH} & \rightarrow \mathrm{Na}_{2} \mathrm{SiF}_{6} \downarrow+2 \mathrm{H}_{2} \mathrm{O} \\
\mathrm{H}_{3} \mathrm{PO}_{4}+\mathrm{NaOH} & \rightarrow \mathrm{NaH}_{2} \mathrm{PO}_{4}+\mathrm{H}_{2} \mathrm{O} \\
\mathrm{HF}+\mathrm{NaOH} & \rightarrow \mathrm{NaF}+\mathrm{H}_{2} \mathrm{O}\end{aligned}$ & $\begin{aligned} 2 \mathrm{H}_{3} \mathrm{PO}_{4}+\mathrm{Ca}(\mathrm{OH})_{2} & \rightarrow \mathrm{Ca}\left(\mathrm{H}_{2} \mathrm{PO}_{4}\right)_{2}+2 \mathrm{H}_{2} \mathrm{O} \\
\mathrm{H}_{2} \mathrm{SiF}_{6}+\mathrm{Ca}(\mathrm{OH})_{2} & \rightarrow \mathrm{CaSiF}_{6} \downarrow+2 \mathrm{H}_{2} \mathrm{O} \\
2 \mathrm{HF}+\mathrm{Ca}(\mathrm{OH})_{2} & \rightarrow \mathrm{CaF}_{2} \downarrow+2 \mathrm{H}_{2} \mathrm{O}\end{aligned}$ \\
\hline $6-9$ & $\begin{array}{c}\mathrm{H}_{2} \mathrm{SiF}_{6}+6 \mathrm{NaOH} \rightarrow 6 \mathrm{NaF}+ \\
\mathrm{SiO}_{2} \cdot \mathrm{nH}_{2} \mathrm{O} \downarrow \\
\mathrm{H}_{3} \mathrm{PO}_{4}+2 \mathrm{NaOH} \rightarrow \mathrm{Na}_{2} \mathrm{HPO}_{4}+2 \mathrm{H}_{2} \mathrm{O}\end{array}$ & $\begin{array}{l}\mathrm{Ca}\left(\mathrm{H}_{2} \mathrm{PO}_{4}\right)_{2}+\mathrm{Ca}(\mathrm{OH})_{2} \rightarrow 2 \mathrm{CaHPO}_{4} \downarrow+2 \mathrm{H}_{2} \mathrm{O} \\
\mathrm{CaSiF}_{6}+\mathrm{Ca}(\mathrm{OH})_{2} \rightarrow \mathrm{CaF}_{2} \downarrow+\mathrm{SiO}_{2} \cdot \mathrm{nH}_{2} \mathrm{O} \downarrow\end{array}$ \\
\hline $9-12$ & $\begin{array}{c}\mathrm{SiO}_{2} \cdot \mathrm{nH}_{2} \mathrm{O}+\underset{(\mathrm{n}+2) \mathrm{H}_{2} \mathrm{O}}{4 \mathrm{NaOH}} \rightarrow \mathrm{Na}_{4} \mathrm{SiOH}+ \\
.\end{array}$ & $2 \mathrm{CaHPO}_{4}+\mathrm{Ca}(\mathrm{OH})_{2} \rightarrow \mathrm{Ca}_{3}\left(\mathrm{PO}_{4}\right)_{2} \downarrow+2 \mathrm{H}_{2} \mathrm{O}$ \\
\hline
\end{tabular}

$\mathrm{NaCl}$ as a precipitating agent was not effective for phosphates, fluorides or odor removal. According to the XRF results, residual concentration of $\mathrm{Cl}^{-}$ions in the wastewater after precipitation increased from $23.8 \mathrm{~g} / \mathrm{L}$ at $\mathrm{pH} 1.7$ up to $182.2 \mathrm{~g} / \mathrm{L}$ at $\mathrm{pH}$ 1.5. The precipitate after the addition of $\mathrm{NaCl}$ has a crystalline structure for the following reasons: at $\mathrm{pH}=1.7$ this is due to the formation of rough sodium hexafluorosilicate crystals (Figure $5 b$ ), and at $\mathrm{pH}=1.5$ it is because of excess $\mathrm{NaCl}$ concentration (Figure 5c). 


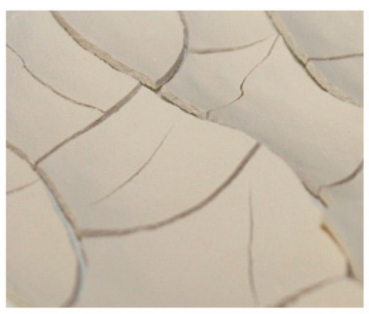

(a)

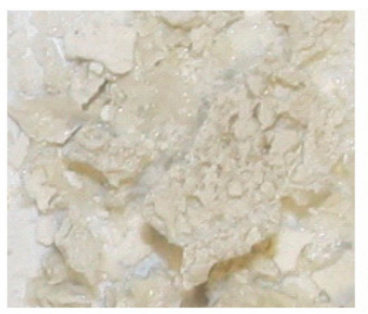

(b)

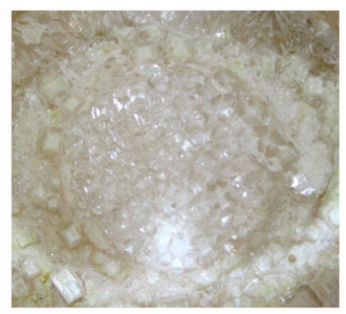

(c)

Figure 5. Wastewater sediment (a) before treatment $(\mathrm{pH}=2)$ and after precipitation with $\mathrm{NaCl}$ (b) $\mathrm{pH}=1.7$, (c) $\mathrm{pH}=1.5$.

\subsubsection{Effect of Metal Hydroxides}

The efficiency of fluoride and phosphate removal obtained after the precipitation with $\mathrm{K}$, Na and Ca hydroxides was studied in the $\mathrm{pH}$ range 4-12.

It was found that $\mathrm{KOH}$ and $\mathrm{NaOH}$ as precipitation agents did not make a considerable difference in the removal efficiency of $\mathrm{PO}_{4}{ }^{3-}$ and $\mathrm{F}^{-}$ions. The recovery of $\mathrm{SiF}_{6}{ }^{2-}$ ions reached a maximum at $\mathrm{pH}$ 6-9 and then decreased with further increases in the $\mathrm{pH}$ (Figure 6). Residual concentration of $\mathrm{Si}$ (measured with the AAS) after precipitation with $\mathrm{NaOH}$ and $\mathrm{KOH}$ at $\mathrm{pH}>9$ increased from $0.24 \mathrm{~g} / \mathrm{L}$ $(\mathrm{pH}=9)$ to $4.13 \mathrm{~g} / \mathrm{L}(\mathrm{pH}=12)$ and from $0.09 \mathrm{~g} / \mathrm{L}(\mathrm{pH}=9)$ to $1.75 \mathrm{~g} / \mathrm{L}(\mathrm{pH}=12)$, respectively.
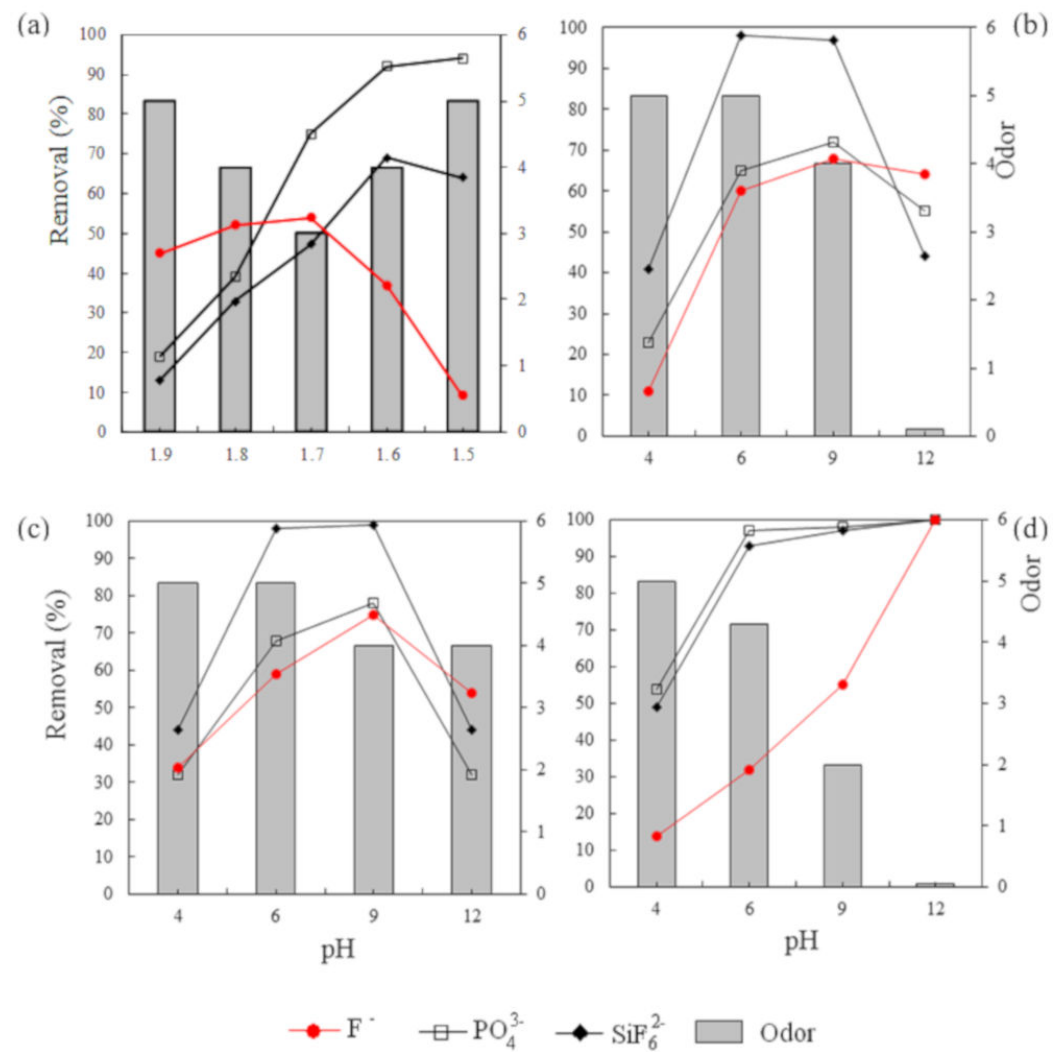

Figure 6. Effect of $\mathrm{pH}$ on treatment efficiency of wastewater with different reagents: (a) sodium chloride 10\% (wt/vol); (b) sodium hydroxide 10\% (wt/vol); (c) potassium hydroxide 10\% (wt/vol); (d) calcium hydroxide $10 \%$ (wt/vol).

The decrease in odor intensity after precipitation with $\mathrm{NaOH}$ can be explained by a reaction between $\mathrm{HF}$ and $\mathrm{NaOH}$ that results in the formation of odorless $\mathrm{NaF}$. By contrast, precipitation with $\mathrm{KOH}$ does not abate odor, as the resulting substance is $\mathrm{KF}$. In fact, at $\mathrm{pH} 12$, after precipitation with $\mathrm{NaOH}$ odor intensity was 0 (not perceptible), whereas after precipitation with $\mathrm{KOH}$ odor intensity was 4 (strong odor). 
As can be seen from the results of the experiments, the use of sodium hydroxide and potassium hydroxide as precipitating agents at $\mathrm{pH}>11$ results in an almost complete removal of smell from the wastewater. However, in the case of the use of sodium hydroxide, with an increase in $\mathrm{pH}>9$, the already dissolved $\mathrm{SiF}_{6}{ }^{2-}$ ions re-dissolve and the effect of fluoride removal does not exceed $75 \%$ (Figure $6 \mathrm{~b}$ ). In the case of lime, at $\mathrm{pH}>11$ the removal of fluorides, phosphates, and odor reached $99 \%$ (Figure 6d). The odor intensity started decreasing after $\mathrm{pH} 9$, due to the decreasing concentration of the $\mathrm{HF}\left(\mathrm{F}^{-}\right)$in wastewater, up to 0 (not perceptible) at $\mathrm{pH}=12$. Residual concentration in the treated wastewater did not exceed the environmental regulation limits.

The experimental results show that, in the case of neutralization of the wastewater with sodium hydroxide up to $\mathrm{pH}=9$, there is a strong and quantitative effect on the removal of phosphorus and fluorine. This can be explained by considering the chemical reactions presented in Table 6 . The use of sodium (potassium) hydroxide leads to the formation of coarser sodium (potassium) hexafluorosilicate and the co-precipitation of amorphous silica, which plays the role of active centers on which phosphate and fluoride ions are deposited.

An increase in the $\mathrm{pH}$ above 10 leads to the re-dissolution of silicon hydroxide and a decrease in the overall effect.

The wastewater had a strong irritating odor due to hydrofluoric and hexafluorosilicic acids. Results of the experiment showed that, after the neutralization with $\mathrm{NaOH}$ and $\mathrm{Ca}(\mathrm{OH})_{2}$, the level of odor decreased from extremely strong to very weak. Instead, when using $\mathrm{KOH}$, the level of odor did not change.

This can be explained by the formation of odorless $\mathrm{CaF}$ and $\mathrm{Na}_{2} \mathrm{SiF}_{6}$ after the precipitation with lime and $\mathrm{NaOH}$ (or $\mathrm{NaCl}$ ) from one side, and $\mathrm{K}_{2} \mathrm{SiF}_{6}$, which has a strong odor, in the second case. The potential-pH diagram obtained for the P-F-Si-Ca system at $25^{\circ} \mathrm{C}$ is plotted in Figure 7 . According to De Luna et al. [22], colloidal silica may result in more effective agglomeration of $\mathrm{CaF}_{2}$, because of particle charge difference (physical adsorption of negative $\mathrm{SiO}_{2}$ on the surface of positively charged $\mathrm{CaF}_{2}$ ), as silica particles play a key role in the nuclei in precipitation of $\mathrm{CaF}_{2}$.

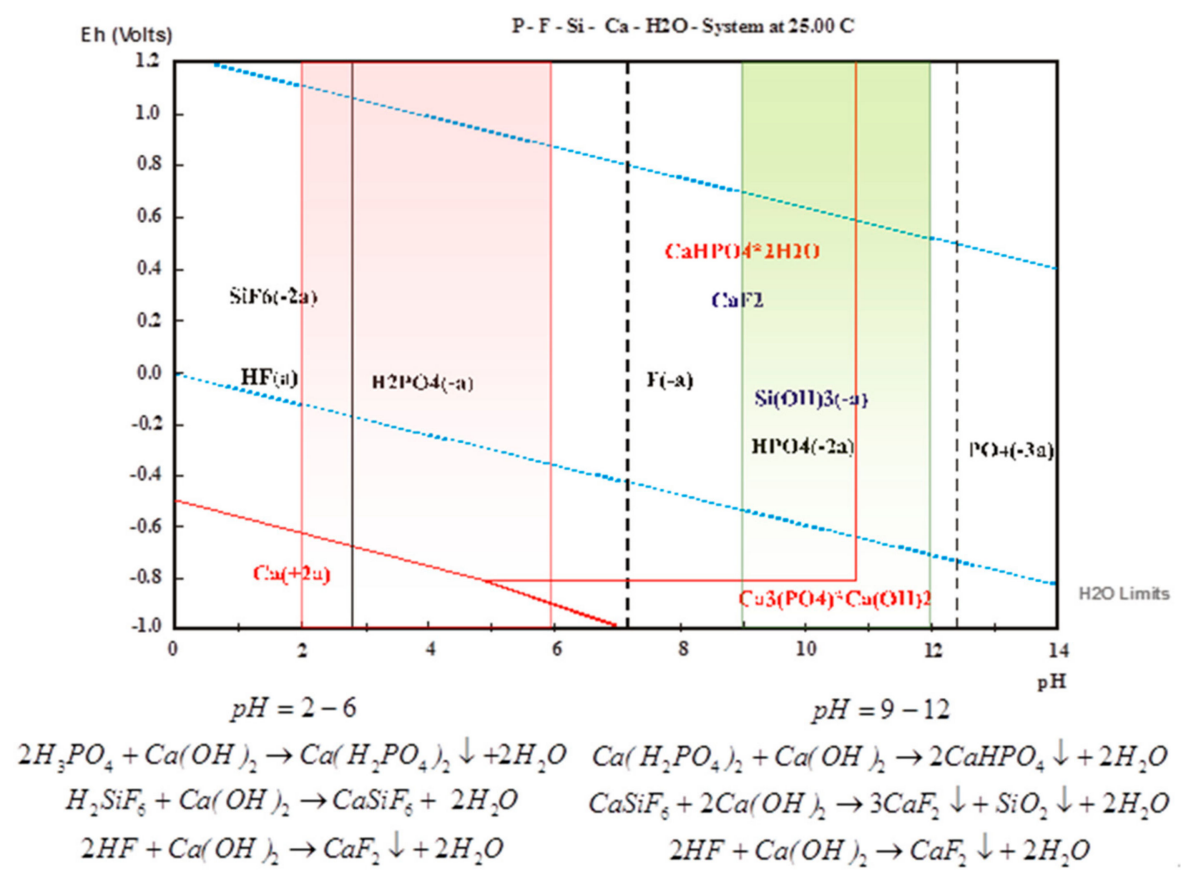

Figure 7. Pourbaix diagram for the P-F-Si-Ca- $\mathrm{H}_{2} \mathrm{O}$ system at $25^{\circ} \mathrm{C}$.

To study the mechanism of fluorides and phosphates removal during the use of hydrated lime, the composition of the produced sludge was studied using different characterization methods such as XRD and FTIR. 
XRD and IR analyses were performed on samples of wastewater (II) before and after precipitation with lime at different $\mathrm{pH}$ values.

The results suggest that fluoride and phosphate removal by hydrated lime is a combination of chemical adsorption on the surfaces of lime particles, ion exchange of $\mathrm{F}^{-}$with $\mathrm{OH}^{-}$and some direct precipitation. Higher values of $\mathrm{pH}$ most likely result in the formation of negatively charged $\mathrm{OH}-$ groups on the surface of the particles. This leads to an enhancement of the sorptive capacity of $\mathrm{Ca}^{2+}$ ions, thus creating favorable conditions for the formation and deposition of calcium-silicate complexes. In simplified form, the following reactions can be written (Table 6).

The XRD patterns (Figure 8) showed characteristic Bragg peaks of $\mathrm{CaF}_{2}$ after precipitation at $\mathrm{pH} 9$ and both of $\mathrm{CaF}_{2}$ and $\mathrm{Ca}(\mathrm{OH})_{2}$ at $\mathrm{pH} 12$, with the latter as a result of its excess in the precipitation process. The obtained IR spectrum (Figure 9) was characteristic of $\mathrm{SiO}_{2} \cdot \mathrm{nH}_{2} \mathrm{O}$ (match 95.27\%) at $\mathrm{pH} 6$ and $\mathrm{Ca}(\mathrm{OH})_{2}$ (match $98.75 \%$ ) at $\mathrm{pH} 12$.

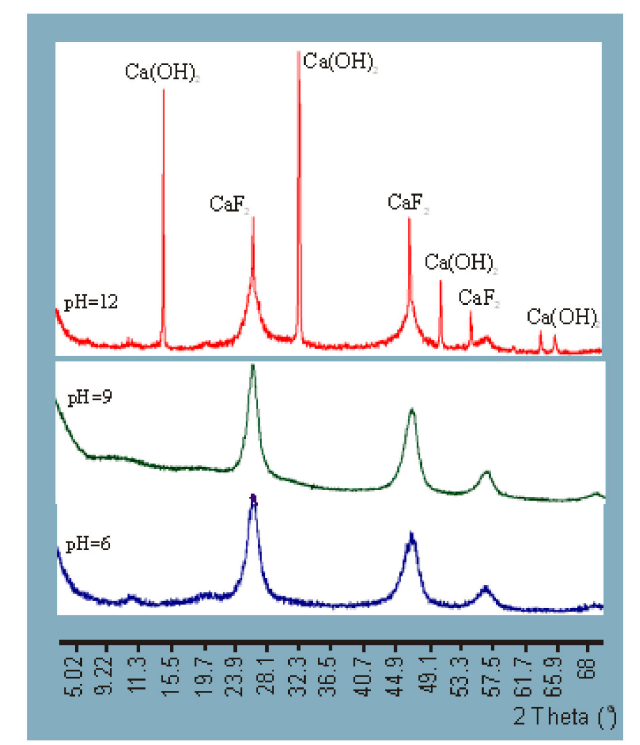

Figure 8. X-ray diffraction (XRD) patterns of the precipitates obtained by the $\mathrm{Ca}(\mathrm{OH})_{2}$ treatment of wastewater (II) at different $\mathrm{pH}$ levels.

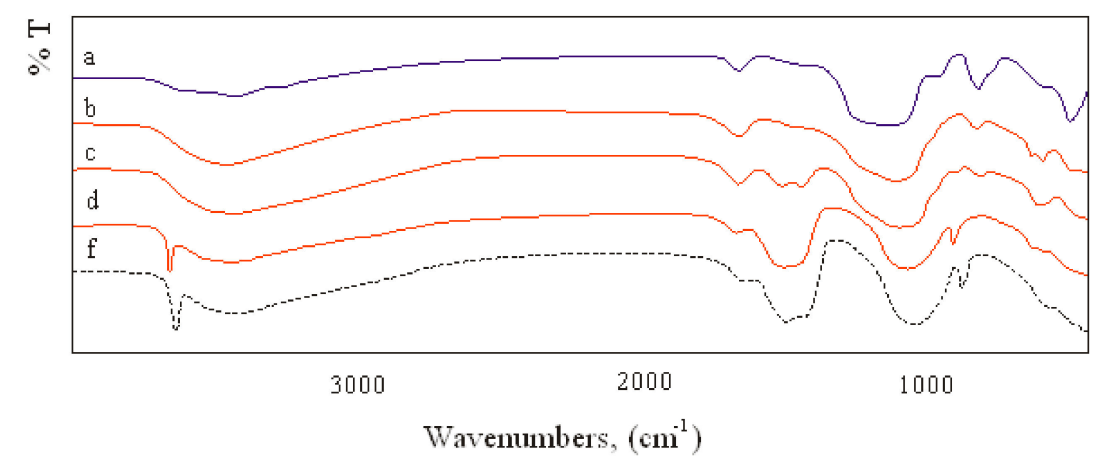

Figure 9. Infrared (IR) spectrum of the precipitate obtained by the $\mathrm{Ca}(\mathrm{OH})_{2}$ treatment of wastewater (II) at different $\mathrm{pH}$ levels: (a) before treatment; after treatment (b) at $\mathrm{pH}=6$, (c) $\mathrm{pH}=9$, (d) $\mathrm{pH}=12$, and (f) $\mathrm{Ca}(\mathrm{OH})_{2}$.

As can be inferred from Figure $6 \mathrm{a}$, the addition of $\mathrm{NaCl}$ up to $\mathrm{pH} 1.7$ led to the formation of $\mathrm{Na}_{2} \mathrm{SiF}_{6}$ and also caused a decrease in odor intensity, resulting in the removal of $\mathrm{F}^{-}$and $\mathrm{PO}_{4}{ }^{3-}$.

The composition of the wastewater after precipitation with $\mathrm{Ca}(\mathrm{OH})_{2}$ at different $\mathrm{pH}$ values is given in Table 7 . No more elements were detected at a concentration greater than $0.01 \% \mathrm{wt}$. 
Table 7. Semi-quantitative analysis of the solid and liquid phase of wastewater after treatment with $\mathrm{Ca}(\mathrm{OH})_{2}$ at different $\mathrm{pH}$ values.

\begin{tabular}{|c|c|c|c|c|c|c|c|}
\hline \multirow{2}{*}{$\mathrm{pH}$} & \multicolumn{7}{|c|}{ Concentration (\%wt) } \\
\hline & Al & Si & $\mathrm{Ca}$ & $\mathrm{Fe}$ & $\mathrm{S}$ & $\mathrm{Cl}$ & $\mathbf{P}$ \\
\hline \multicolumn{8}{|c|}{ Solid Phase } \\
\hline 6 & 0.23 & 16.22 & 75.77 & 0.30 & 0.016 & 0.58 & 6.86 \\
\hline 9 & 0.23 & 16.22 & 74.88 & 0.26 & 0.033 & 0.72 & 7.62 \\
\hline 12 & 0.21 & 8.67 & 86.14 & 0.19 & 0.028 & 0.43 & 4.36 \\
\hline \multicolumn{8}{|c|}{ Liquid Phase } \\
\hline 6 & 0.01 & 0.027 & 0.03 & 0.002 & 0.001 & 0.189 & 0.0009 \\
\hline 9 & 0.02 & 0.019 & 0.04 & 0.001 & 0.047 & 0.046 & 0.0002 \\
\hline 12 & 0.10 & 0.004 & 0.04 & 0.001 & 0.001 & 0.044 & 0.0001 \\
\hline
\end{tabular}

\section{Conclusions}

This work investigated possible ways to treat wastewater from a fertilizer plant containing $\mathrm{H}_{3} \mathrm{PO}_{4}$ and fluoride ions, which were present in both "free" (HF) and combined form $\left(\mathrm{H}_{2} \mathrm{SiF}_{6}\right)$.

As illustrated, several different reagents were tested to figure out the reaction mechanisms. In the end, hydrated lime was found to be the most effective reagent, as in its presence dangerous $\mathrm{PO}_{4}{ }^{3-}$, $\mathrm{SiF}_{6}{ }^{2-}, \mathrm{F}^{-}$ions would convert into their insoluble calcium-based salts. It was also found that process efficiency is highly depending on the fine-tuning of $\mathrm{pH}$.

Finally, it was found that as the resulting suspension is not hazardous, it can be recycled in the plant process for the granulation stage of fertilizer production, thus achieving ZLD conditions for the wastewater treatment.

The main and final finding of the research was therefore that the use of $\mathrm{Ca}(\mathrm{OH})_{2}$ as a precipitating reagent, at $\mathrm{pH} 12$, results in the possibility of recycling the wastewater without further filtration steps (Figure 10). This is due to the conversion into non-hazardous solid forms of $99.9 \%$ of the formerly hazardous and soluble phosphates and fluorides.

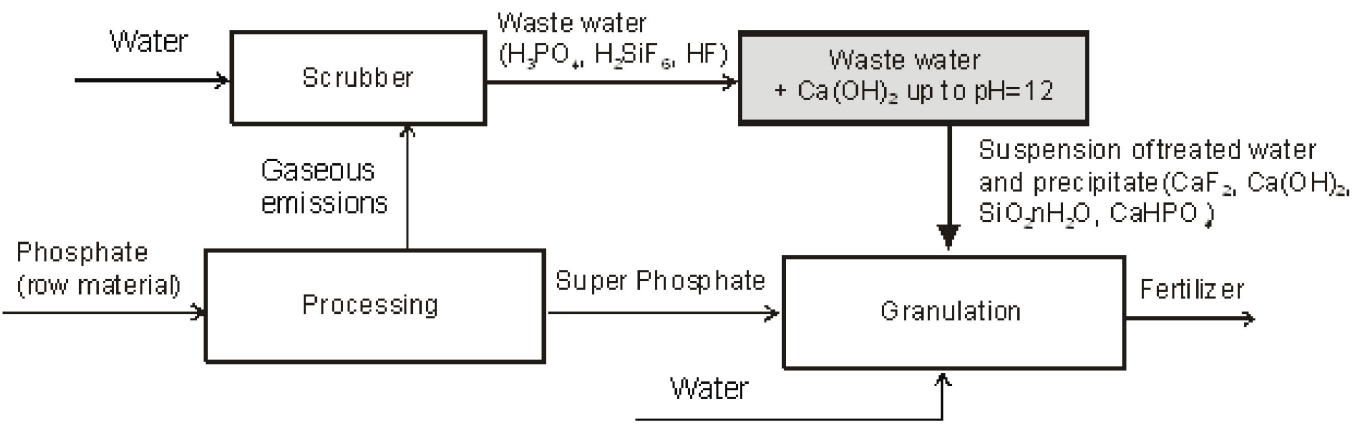

Figure 10. Flowchart of the process.

Author Contributions: Conceptualization, F.V.; methodology, S.B.Z.; validation, I.P.; investigation, S.B.Z.; data curation, I.D.M.; writing—original draft preparation, S.B.Z.; XRD analyses, G.T.; writing—review and editing, F.F.; visualization, I.D.M.; supervision, F.V. All authors have read and agreed to the published version of the manuscript.

Funding: This research did not receive any specific grant from funding agencies in the public, commercial, or not-for-profit sector.

Acknowledgments: The authors are very grateful to Fabiola Ferrante and Marcello Centofanti for their helpful collaboration given for the XRF and AAS analyses.

Conflicts of Interest: The authors declare no conflict of interest. 


\section{References}

1. Sarawadea, P.B.; Jong-Kil, K.; Hilongaa, A.; Kima, H.T. Recovery of high surface area mesoporous silica from waste hexafluorosilicic acid $\left(\mathrm{H}_{2} \mathrm{SiF}_{6}\right)$ of fertilizer industry. J. Hazard. Mater. 2010, 173, 576-580. [CrossRef] [PubMed]

2. Elineema, G.; Kim, J.K.; Hilonga, A.; Shao, G.N.; Kim, Y.N.; Quang, D.V.; Sarawade, P.B.; Kim, H.T. Quantitative recovery of high purity nanoporous silica from waste products of the phosphate fertilizer industry. J. Ind. Eng. Chem. 2013, 19, 63-67. [CrossRef]

3. Kumar, M.; Nani Babu, M.; Mankhand, T.R.; Pandey, B.D. Precipitation of sodium silicofluoride $\left(\mathrm{Na}_{2} \mathrm{SiF}_{6}\right)$ and cryolite $\left(\mathrm{Na}_{3} \mathrm{AlF}_{6}\right)$ from $\mathrm{HF} / \mathrm{HCl}$ leach liquors of alumino-silicates. Hydrometallurgy 2010, 104, $304-307$. [CrossRef]

4. Lu, N.C.; Liu, J.C. Removal of phosphate and fluoride from wastewater by a hybrid precipitation-microfiltration process. Sep. Purif. Technol. 2010, 74, 329-335. [CrossRef]

5. Khatibikamal, V.; Torabian, A.; Janpoor, F.; Hoshyaripour, G. Fluoride removal from industrial wastewater using electrocoagulation and its adsorption kinetics. J. Hazard. Mater. 2010, 179, 276-280. [CrossRef] [PubMed]

6. Dolar, D.; Košutić, K.; Vučić, B. RO/NF treatment of wastewater from fertilizer factory-Removal of fluoriden and phosphate. Desalination 2011, 265, 237-241. [CrossRef]

7. Liu, J.C. Recovery of phosphate and ammonia as struvite from semiconductor wastewater. Sep. Purif. Technol. 2009, 64, 368-373.

8. Aldaco, R.; Garea, A.; Irabien, A. Calcium fluoride recovery from fluoride wastewater in a fluidized bed reactor. Water Res. 2007, 41, 810-818. [CrossRef] [PubMed]

9. Batiha, M.; Al-Harahsheh, M. The effect of reaction conditions on the precipitation of sodium hexafluorosilicate produced from waste hexafluorosilicic acid. Pol. J. Chem. Tech. 2011, 13, 23-28. [CrossRef]

10. Gouider, M.; Feki, M.; Sayadi, S. Separative recovery with lime of phosphate and fluoride from an acidic effluent containing $\mathrm{H}_{3} \mathrm{PO}_{4}, \mathrm{HF}$ and/or $\mathrm{H}_{2} \mathrm{SiF}_{6}$. J. Hazard. Mater. 2009, 170, 962-968. [CrossRef] [PubMed]

11. Chimenos, J.M.; Fernandez, A.I.; Hernandez, A.; Haurie, L.; Espiell, F.; Ayora, C. Optimization of phosphate removal in anodizing aluminium wastewater. Water Res. 2006, 40, 137-143. [CrossRef] [PubMed]

12. Nath, S.K.; Borodoloi, S.; Dutta, R.K. Effect of acid on morphology of calcite during acid enhanced defluoridation. J. Fluorine Chem. 2011, 132, 19-26. [CrossRef]

13. Nath, S.K.; Dutta, R.K. Acid-enhanced limestone defluoridation in column reactor using oxalic acid. Process Saf. Environ. Prot. 2012, 90, 65-75. [CrossRef]

14. Innocenzi, V.; Zueva, S.; Prisciandaro, M.; De Michelis, I.; Di Renzo, A.; Mazziotti di Celso, G.; Vegliò, F. Treatment of TMAH solutions from the microelectronics industry: A combined process scheme. J. Water Proc. Engin. 2019, 31, 100780. [CrossRef]

15. Grzmil, B.; Wronkowski, J. Removal of phosphates and fluorides from industrial wastewater. Desalination 2006, 189, 261-268. [CrossRef]

16. Aoudj, S.; Drouiche, N.; Hecini, M.; Ouslimane, T.; Palaouane, B. Coagulation as a Post-Treatment Method for the Defluoridation of Photovoltaic Cell Manufacturing. Procedia Eng. 2012, 33, 111-120. [CrossRef]

17. Henßge, A.; Acker, J. Chemical analysis of acidic silicon etch solutions. Titrimetric determination of $\mathrm{HNO}_{3}$, $\mathrm{HF}$, and $\mathrm{H}_{2} \mathrm{SiF}_{6}$. Talanta 2007, 73, 220-226.

18. Henßge, A.; Acker, J.; Müller, C. Titrimetric determination of silicon dissolved in concentrated $\mathrm{HF}_{-} \mathrm{HNO}_{3}$ etching solutions. Talanta 2006, 68, 581-585. [CrossRef] [PubMed]

19. Weinreich, W.; Acker, J.; Graber, I. Determination of total fluoride in $\mathrm{HF} / \mathrm{HNO}_{3} / \mathrm{H}_{2} \mathrm{SiF}_{6}$ etch solutions by new potentiometric titration methods. Talanta 2007, 71, 1901-1905. [CrossRef] [PubMed]

20. Odor Methodology Guideline, Department of Environmental Protection, Perth, Western Australia March. ISBN 073076672 1. Available online: https://www.der.wa.gov.au/images/documents/your-environment/air/ publications/odour-methodology-guidelines.pdf (accessed on 4 November 2019). 
21. Zumdahl, S.S.; Zumdahl, S.A. Chemistry, 7th ed.; Houghton Mifflin Company: New York, NY, USA, 2007.

22. De Luna, M.D.G.; Warmadewanthi; Liu, J.C. Combined treatment of polishing wastewater and fluoride-containing wastewater from a semiconductor manufacturer. Coll. Surf. A Physicochem. Eng. Aspects 2009, 347, 64-68. [CrossRef] 